\title{
Endoscopic resection is more effective than biopsy or EUS to detect residual rectal neuroendocrine tumor ${ }^{*}$
}

\section{다)(1) $\odot$}

\section{Authors}

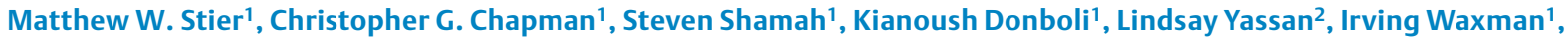
Uzma D. Siddiqui ${ }^{1}$

\section{Institutions}

1 University of Chicago Center for Endoscopic Research and Therapeutics (CERT), Chicago, Illinois, United States

2 Department of Pathology, the University of Chicago Medicine, Chicago, Illinois, United States

submitted 1.4 .2020

accepted after revision 5.10 .2020

Bibliography

Endoscopy International Open 2021; 09: E4-E8

DOI 10.1055/a-1300-1017

ISSN 2364-3722

(c) 2021. The Author(s).

This is an open access article published by Thieme under the terms of the Creative Commons Attribution-NonDerivative-NonCommercial License, permitting copying and reproduction so long as the original work is given appropriate credit. Contents may not be used for commecial purposes, or adapted, remixed, transformed or built upon. (https://creativecommons.org/licenses/by-nc-nd/4.0/)

Georg Thieme Verlag KG, Rüdigerstraße 14,

70469 Stuttgart, Germany

Corresponding author

Uzma D. Siddiqui, MD, FASGE, University of Chicago Center for Endoscopic Research and Therapeutics (CERT), $5700 \mathrm{~S}$ Maryland Ave, MC 8043, Chicago, IL 60637, United States Fax: +1-773-834-8891

usiddiqui@bsd.uchicago.edu

\section{ABSTRACT}

Background and study aims Rectal neuroendocrine tumors (NETs) are often discovered incidentally and may be misidentified as adenomatous polyps. This can result in a partial resection at the index procedure, and lesions are often referred for staging or evaluation for residual disease at the resection site. The aim of this study was to identify the ideal method to confirm complete excision of small rectal NETs.

Patients and methods Data from patients with a previously resected rectal NET referred for follow-up endoscopy or endoscopic ultrasound (EUS) were retrospectively reviewed. Univariate analysis was performed on categorical data using the Chi-squared test.

Results Forty-nine patients with rectal NETs were identified by pathology specimens. Of those, 39 underwent follow-up endoscopy or EUS and were included. Baseline characteristics included gender $(71 \% \mathrm{~F}, 29 \% \mathrm{M})$, age $(57.2 \pm$ $13.4 \mathrm{yrs})$ lesion size $(7.3 \pm 4.2 \mathrm{~mm})$ and location. The prior resection site was identified in 37/39 patients who underwent tissue sampling. Residual NET was found histologically in 14/37 lesions. All residual disease was found during salvage endoscopic mucosal resection (EMR) or endoscopic submucosal dissection (ESD) and $43 \%$ had a normal-appearing scar. Every patient undergoing EUS had an unremarkable exam. Initial cold biopsy polypectomy $(P=$ 0.006), visible lesions $(P=0.001)$ and EMR/ESD of the prior resection site $(P=0.01)$ correlated with residual NET.

Conclusions Localized rectal NETs may be incompletely removed with standard polypectomy. If an advanced resection is not performed initially, repeat endoscopy with salvage EMR or ESD of the scar should be considered. For small rectal NETs, biopsy may miss residual disease when there is no visible lesion and EUS appears to have no benefit.

\section{Introduction}

Gastrointestinal neuroendocrine tumors (NETs) are increasingly being recognized due to the widespread availability of flexible endoscopic procedures [1-4]. The rectum is a common site for diagnosis, comprising roughly $18 \%$ of all NETs and one-third of gastrointestinal NETs in the United States. Although the incidence of rectal NETs has been steadily rising in recent decades

\footnotetext{
* Meeting presentations: Digestive Disease Week 2018
}

[5] the majority of rectal NETs are detected at an early stage and carry a favorable overall prognosis with 5-year survival approaching $88 \%[1,6,8]$. European and American guidelines recommend endoscopic resection for NETs under $10 \mathrm{~mm}$ that are confined to the mucosa or submucosa (T1) without high risk features, and note endoscopic resection can be considered in lesions under $20 \mathrm{~mm}[1,2,9,10]$.

Endoscopic ultrasound (EUS) has typically been part of the staging workup when a rectal NET has been identified. EUS can 
be applied to facilitate local staging and has been shown to correlate well with depth of invasion and histopathology specimens in larger tumors $[11,12]$. In addition, it can aid in the selection of an appropriate resection modality when choosing between endoscopic and surgical resection techniques [11]. However, EUS may not be required for diminutive or smaller lesions due to their low rate of locally advanced disease or distant metastases $[13,14]$

Despite increasing detection rates and improvements in local staging, the overall incidence of rectal NETs remains low at 1.05 per 100,000 adults [29]. One study demonstrated a prevalence of $0.17 \%$ for NETs on screening colonoscopy, which is significantly lower than that of adenomatous and hyperplastic polyps [16]. Given their relative infrequency, rectal NETs may be misidentified as adenomatous or hyperplastic polyps at the time of index colonoscopy and removed via standard polypectomy techniques. Studies have demonstrated that standard polypectomy or biopsy forcep removal is insufficient for complete excision due to frequent submucosal involvement of carcinoid tissue, with rates of complete resection as low as $20 \%$ to $30 \%$ in some settings $[3,7,18]$.

Endoscopic mucosal resection (EMR) is widely available and more effective at removing submucosal tissue, however reported rates of complete resection for rectal NETs remain variable (72\%-100\%) [19]. Furthermore, there can be significant discrepancy between endoscopic assessment of complete resection and pathology findings [20]. EMR techniques including submucosal injection of saline (with or without dye), band ligation, and cap-assisted, have shown promise to improve complete histologic resection with limited additional procedural time and an acceptable complication profile [21-24]. Endoscopic submucosal dissection (ESD) is another technique that has become more widely available in western centers and has a role in en-bloc removal of rectal NETs, particularly in a salvage therapy setting due to scarring from prior resection attempts $[25,26]$.

Guidelines on surveillance and salvage therapy for residual carcinoid tissue after standard polypectomy and the effectiveness of EUS and surveillance biopsy in that setting are limited. In this study we present a cohort of patients with rectal NETs who were referred for EUS staging or follow-up endoscopy after an initial attempt at endoscopic removal.

\section{Patients and methods}

Procedural data tracking software (Provation MD, Minneapolis, Minnesota, United States) and gastrointestinal pathology records were queried for "neuroendocrine tumor" and "carcinoid." These search results were further stratified by location to include only colonic specimens obtained during colonoscopy or flexible sigmoidoscopy. Patients referred for staging or follow-up endoscopy after initial endoscopic removal of a rectal NET were reviewed. Patients who did not complete follow-up endoscopy were excluded. Two patients underwent follow-up endoscopy without tissue sampling due to inability of the endoscopist to adequately identify the prior resection site. These cases were excluded from analysis on NET recurrence, but still received full rectal EUS for staging and these data were included. All cases occurred between February 2007 and May 2018. Procedures were performed by three therapeutic endoscopists at a quaternary care, urban academic medical center.

Patients that were referred for a follow-up endoscopy at our center and had tissue sampling of the scar from prior resection attempt to assess for the presence of residual neuroendocrine tissue were reviewed retrospectively. Baseline patient and lesion information including age, gender, anatomic location, lesion size, initial resection technique and histopathology were reviewed. Endoscopic appearance of the prior resection site, size and description of any visible lesions, EUS findings (if performed), method of tissue sampling and the presence of residual NET on histopathology in follow-up were also noted. Tissue sampling occurred in the form of biopsy alone, EMR or ESD of the previous resection site, and the sampling method was chosen by the endoscopist on a case-by-case basis. EUS was performed on a number of patients at the discretion of the endoscopist. Raw percentages were obtained for rate of residual NET across a variety of procedural variables. A univariate analysis was then performed to identify categorical variables that impacted the likelihood of residual rectal NET after initial polypectomy. Categorical variables were analyzed for association with the outcome of interest using the Chi-squared test.

\section{Results}

A total of 49 patients with colorectal NETs were initially identified based on pathology specimens. From the initial cohort, 39 patients received follow-up endoscopy with or without EUS to assess for residual neuroendocrine tumor. The average patient age was $57.2 \pm 13.4$ years and $71 \%$ were female. Lesion size was reported in 29 index procedures with an average of $7.3 \pm 4.2 \mathrm{~mm}$ (range 1-20 mm), including six lesions between 11 and $20 \mathrm{~mm}$. All lesions were located in the rectum or rectosigmoid. Histologic examination identified all NETs to be classified as lowgrade lesions. Primary resection technique was available in 27/ 39 cases and included cold biopsy polypectomy ( $n=14$, average size $4 \mathrm{~mm}$ ), snare removal with or without the application of electrocautery $(n=8$, average size $11.5 \mathrm{~mm})$, EMR $(n=4$, average size $8.75 \mathrm{~mm})$ and ESD $(\mathrm{n}=1$, size $20 \mathrm{~mm})(\triangleright$ Table 1$)$. The

Table 1 Baseline characteristics

\begin{tabular}{|l|l|}
\hline Age & $\mathbf{5 7 \pm 1 3 . 4}$ yrs \\
\hline Sex $(\% \mathrm{~F} / \% \mathrm{M})$ & $71 / 29$ \\
\hline Lesion size & $7.3 \pm 4.2 \mathrm{~mm}$ \\
\hline Lesions with histology & $37 / 39$ \\
\hline Initial resection technique & $\begin{array}{l}\text { Cold biopsy }-14 \\
\text { Snare }-8\end{array}$ \\
\hline & $\begin{array}{l}\text { EMR }-4 \\
\text { ESD }-1 \\
\text { Not reported - } 12\end{array}$ \\
\hline $\begin{array}{l}\text { EMR, endoscopic mucosal resection; ESD, endoscopic submucosal dissec- } \\
\text { tion }\end{array}$ \\
\hline
\end{tabular}


previous resection site was successfully identified in 37/39 cases during follow-up endoscopy ( $\triangleright$ Fig. 1 ).

The resection site was described as a healthy-appearing scar in 27 cases and a scar plus a visible lesion in 10 cases. All patients in whom the initial resection site was identified underwent tissue sampling for histology with biopsy alone $(n=8)$, EMR $(n=27)$ or ESD $(n=2)$ at the discretion of the endoscopist ( $\downarrow$ Table 2). There was evidence of residual NET identified on histologic specimens in $38 \%$ of cases $(n=14)$, all of which were discovered through EMR or ESD of the initial resection site ( Fig.2). These EMR and ESD samples harboring residual NET were all found to have negative resection margins on final pathology.

Of these 14 cases of residual disease, six ( $43 \%$ ) had a normalappearing scar endoscopically. There were a total of 27 patients that had a normal appearing scar, therefore residual NET in this group was six of 27 (22\%). No patients who received biopsy alone for tissue sampling in follow-up were found to have evidence of residual disease. EUS evaluation of the previous resection site was performed in 31 of 39 patients, with all except for one case being sonographically normal. One patient had subtle thickening of the lower mucosa and upper submucosal layers; however, EMR of the site was performed with normal histology.

Resection margins from the initial procedure were involved in 20 of 39 lesions prior to referral to our center for follow-up endoscopy or EUS, but this did not correlate with residual disease $(P=0.39)$ found on subsequent tissue sampling. Initial cold biopsy polypectomy $(P=0.005)$ and endoscopically visible lesions aside from a normal scar $(P=0.001)$ correlated with residual NET on subsequent endoscopy in univariate analysis ( $\triangleright \mathrm{Ta}$ ble 3). EMR or ESD of the scar during follow-up endoscopy as opposed to standard biopsy sampling alone was more likely to discover residual NET $(P=0.012)$ in this cohort.

Preventative hemostasis was applied in $93 \%$ of patients that underwent EMR or ESD for sampling of the previous resection site, with $15 \%$ of those receiving more than one modality. Endoscopic clips $(n=26)$, argon plasma coagulation $(n=3)$ and bipolar electrocautery $(n=2)$ were utilized. There was one perforation (3.4\%) and one episode of delayed bleeding (3.4\%) after EMR in this cohort, both of which were treated endoscopically. There were no other significant complications reported.

\section{Discussion}

Endoscopic resection is safe and feasible for localized rectal NETs under $20 \mathrm{~mm}$ in diameter; however, greater awareness during screening colonoscopy and selection of appropriate endoscopic resection modalities are needed. Current guidelines state there are insufficient comparative data to recommend a specific endoscopic resection technique but acknowledge a risk of positive margins after conventional polypectomy $[1,2]$. Due to the high rate of submucosal involvement, EMR or ESD should be considered first line therapy if a localized rectal NET is suspected on initial endoscopic evaluation to increase the chances of a complete and curative resection [24-28]. Often times multiple resections are required to achieve $\mathrm{R} 0$ resection if biopsy or polypectomy alone are performed during the
49 patients identified with rectal NET on pathology

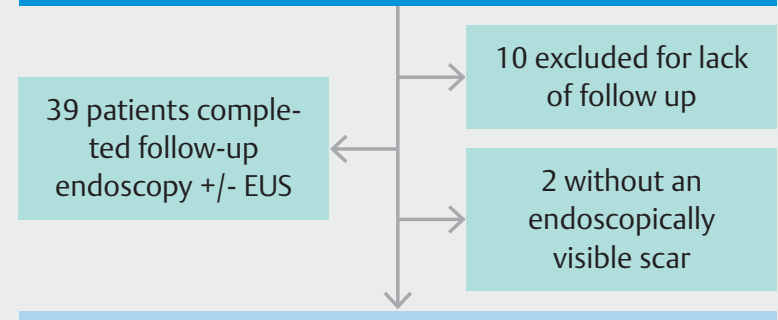

37 patients with sampling of prior resection site

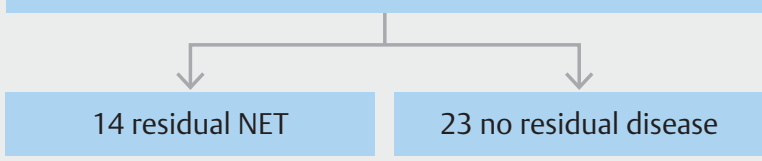

- Fig. 1 Study flowchart.

Table 2 Results of scar evaluation with resection and EUS.

\begin{tabular}{|c|c|}
\hline Residual NET & $14 / 37$ \\
\hline Appearance & $\begin{array}{l}\text { Healthy Scar - } 27 \\
\text { Scar plus lesion - } 10\end{array}$ \\
\hline EUS & 31 - No residual disease \\
\hline Tissue acquisition & $\begin{array}{l}\text { Biopsy - } 8 \\
\text { EMR - } 27 \\
\text { ESD - } 2\end{array}$ \\
\hline Preventative hemostasis & $\begin{array}{l}\text { Bicap - } 2 \\
\text { Clip - } 26 \\
\text { APC - } 3\end{array}$ \\
\hline Complications & $\begin{array}{l}\text { Bleeding - } 1 \\
\text { Perforation - } 1\end{array}$ \\
\hline
\end{tabular}
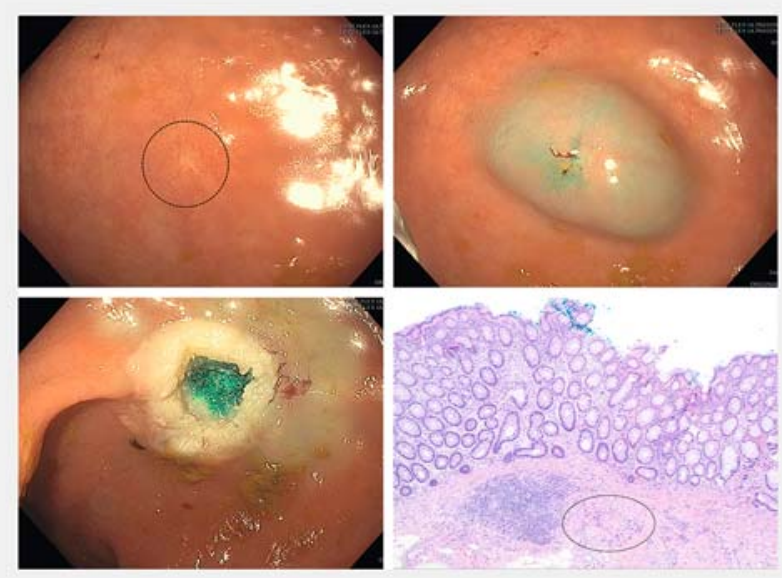

- Fig. 2 Top left: Healthy-appearing scar after initial resection. Top right: Saline lift for EMR of the scar. Bottom left: EMR resection site. Bottom right: Histopathology showing residual carcinoid tissue. 
- Table 3 Factors associated with residual neuroendocrine tumor (NET).

\begin{tabular}{|l|l|l|l|l|}
\hline Factor & N & Odds ratio & P value & $95 \%$ confidence interval (CI) \\
\hline Initial resection with positive margins & 20 & 1.97 & 0.52 & $(0.4-9.5)$ \\
\hline Initial cold biopsy polypectomy & 14 & 7.2 & $0.006^{1}$ & $(1.6-31.2)$ \\
\hline Visual appearance other than normal scar & 10 & 14 & $0.001^{1}$ & $(2.3-84.3)$ \\
\hline 1 statistically significant & & & & \\
\hline
\end{tabular}

initial therapeutic endoscopy, especially for larger lesions (10 $20 \mathrm{~mm}$ ) [29]. If a lesion is suspected to be a rectal NET (i. e. firm, yellow hued, well-circumscribed lesion) during index colonoscopy and local expertise at EMR/ESD is not available, an initial cold biopsy may be performed to confirm the diagnosis followed by prompt referral for consideration of further staging and therapy [1-2]. When conventional resection techniques are applied to a suspected NET in the colon or rectum, careful description of the location and/or tattoo placement adjacent to the lesion may be helpful in future identification of the site for staging and salvage therapy in the event that neuroendocrine tissue is identified [1].

If a rectal NET has been inadvertently identified as an adenomatous or hyperplastic polyp and removed by conventional snare or cold biopsy polypectomy, referral for salvage EMR, modified EMR, or ESD should be strongly considered to ensure complete resection and obviate the need for close surveillance $[24,26,27]$. Our cohort demonstrates that regardless of deep margin findings on initial histopathology, EMR or ESD of the scar during follow up identifies residual microscopic neuroendocrine tissue in as many as one third of patients. Many of the patients with residual disease (22\%) identified on pathologic specimens had a normal-appearing scar at time of follow-up endoscopy, highlighting the need for salvage therapy due to the submucosal origin of most NETs. Cold biopsy polypectomy on initial examination, in particular, was an independent predictor of residual carcinoid tissue found on subsequent endoscopy in univariate analysis. This raises concern that cold biopsy and possibly conventional snare specimens may be too superficial to adequately excise submucosal neuroendocrine tissue, as has been previously demonstrated for diminutive adenomatous and hyperplastic polyps [30-32]. Specimens from piecemeal cold biopsy polypectomy may also be architecturally distorted, and hot biopsy or snare removal often contains cautery artifact that can interfere with accurate identification of the deep margin [3334].

Routine long-term endoscopic surveillance is not recommended after complete resection of a localized rectal NET given the low likelihood of residual disease; however, it is recognized that a small percentage may experience late recurrence $[1,2]$. Follow-up endoscopy with EUS has been used for local staging in rectal NETs. However, EUS may be insensitive for the detection of small residual NET confined to the mucosa or superficial submucosa as demonstrated in this cohort. In fact, our data demonstrate that EUS did not add any additional infor- mation and we suggest that it should not be performed for surveillance of small rectal NETs $<10 \mathrm{~mm}$ in size.

Limitations of this study include its retrospective design and small sample size. Furthermore, on follow-up endoscopy, not all patients underwent EMR or ESD of the prior resection scar. Some patients only underwent biopsy sampling alone, and therefore it is not certain that those patients did not have residual disease beyond the reach of standard cold biopsy specimens. Follow-up for the purposes of this study was providerdependent, which may have introduced selection bias in regards to tissue sampling and residual disease.

\section{Conclusions}

Management of rectal NETs that are confined to the mucosa or submucosa can be achieved using predominately endoscopic methods, which offer the potential for curative resection with minimally invasive techniques. EMR, ESD, or hybrid EMR/ESD techniques should be considered first line in the treatment of localized disease and should ideally be applied during the index procedure to ensure complete resection and potentially obviate the need for further procedures. Increased provider awareness at the time of screening procedures and appropriate referral for consideration of advanced endoscopic modalities are needed. However, when a lesion is misidentified or removed via conventional polypectomy techniques, such as snare or biopsy forceps, endoscopic follow-up with salvage EMR or ESD of the scar should be performed due to the high rate of residual disease due to submucosal involvement.

\section{Competing interests}

The authors declare that they have no conflict of interest.

\section{References}

[1] Anthony LB, Strosberg JR, Klimstra DS et al. The NANETS Consensus Guidelines for the Diagnosis and Management of Gastrointestinal Neuroendocrine Tumors (NETs): Well-Differentiated NETs of the Distal Colon and Rectum. Pancreas 2010; 39: 767-774

[2] Caplin M, Sundin A, Nillson O et al. ENETS Consensus Guidelines for the management of patients with digestive neuroendocrine neoplasms: colorectal neuroendocrine neoplasms. Neuroendocrinology 2012; 95: 88-97 
[3] Chablaney S, Zator ZA, Kumta NA. Diagnosis and management of rectal neuroendocrine tumors. Clin Endosc 2017; 50: 530-536

[4] Dasari A, Shen C, Halperin D et al. Trends in the incidence, prevalence, and survival outcomes in patients with neuroendocrine tumors in the United States. JAMA Oncol 2017; 3: 1335-1342

[5] Yao JC, Hassan M, Phan A et al. One hundred years after "carcinoid": epidemiology of and prognostic factors for neuroendocrine tumors in 35,825 cases in the United States. J Clin Oncol 2008; 26: 3063-3072

[6] Tsikitis VL, Wertheim BC, Guerrero MA. Trends of incidence and survival of gastrointestinal neuroendocrine tumors in the United States: a seer analysis. J Cancer 2012; 3: 292-302

[7] Modlin IM, Lye KD, Kidd M. A 5-decade analysis of 13,715 carcinoid tumors. Cancer 2003; 97: 934-959

[8] de Mestier L, Brixi H, Gincul R et al. Updating the management of patients with rectal neuroendocrine tumors. Endoscopy 2013; 45: 1039-1046

[9] Ramage JK, De Herder WW, Delle Fave G et al. ENETS Consensus Guidelines Update for Colorectal Neuroendocrine Neoplasms. Neuroendocrinology 2016; 103: 139-143

[10] Chung TP, Hunt SR. Carcinoid and neuroendocrine tumors of the colon and rectum. Clin Colon Rectal Surg 2006; 19: 45-48

[11] Ishii N, Horiki N, Itoh T et al. Endoscopic submucosal dissection and preoperative assessment with endoscopic ultrasonography for the treatment of rectal carcinoid tumors. Surg Endosc 2010; 24: 14131419

[12] Kobayashi K, Katsumata T, Yoshizawa S et al. Indications of Endoscopic polypectomy for rectal carcinoid tumors and clinical usefulness of endoscopic ultrasonography. Dis Colon Rectum 2005; 48: 285

[13] Matsumoto T, lida M, Suekane $\mathrm{H}$ et al. Endoscopic ultrasonography in rectal carcinoid tumors: contribution to selection of therapy. Gastrointest Endosc 1991; 37: 539-542

[14] Park SB, Kim DJ, Kim HW et al. Is endoscopic ultrasonography essential for endoscopic resection of small rectal neuroendocrine tumors? World J Gastroenterol 2017; 23: 2037-2043

[15] Fraenkel M, Kim M, Faggiano A et al. Incidence of gastroenteropancreatic neuroendocrine tumours: a systematic review of the literature. Endocr Relat Cancer 2014; 21: R153-163

[16] Jung YS, Yun KE, Chang Y et al. Risk factors associated with rectal neuroendocrine tumors: a cross-sectional study. Cancer Epidemiol Biomarkers Prev 2014; 23: 1406-1413

[17] Son HJ, Sohn DK, Hong CW et al. Factors associated with complete local excision of small rectal carcinoid tumor. Int J Colorectal Dis 2013; 28: 57-61

[18] Onozato Y, Kakizaki S, lizuka $\mathrm{H}$ et al. Endoscopic treatment of rectal carcinoid tumors. Dis Colon Rectum 2010; 53: 169-176

[19] Kim J, Kim JH, Lee JY et al. Clinical outcomes of endoscopic mucosal resection for rectal neuroendocrine tumor. BMC Gastroenterol 2018; 18: 77
[20] Park CH, Cheon JH, Kim JO et al. Criteria for decision making after endoscopic resection of well-differentiated rectal carcinoids with regard to potential lymphatic spread. Endoscopy 2011; 43: 790-795

[21] Yang DH, Park Y, Park SH et al. Cap-assisted EMR for rectal neuroendocrine tumors: comparisons with conventional EMR and endoscopic submucosal dissection (with videos). Gastrointest Endosc 2016; 83: 1015-1022; quiz 1023-e1016

[22] Zhou X, Xie H et al. Endoscopic resection therapies for rectal neuroendocrine tumors: a systematic review and meta-analysis. J Gastroenterol Hepatol 2014; 29: 259-268

[23] Sekiguchi M, Sekine S, Sakamoto T et al. Excellent prognosis following endoscopic resection of patients with rectal neuroendocrine tumors despite the frequent presence of lymphovascular invasion. J Gastroenterol 2015; 50: 1184-1189

[24] Jeon SM, Lee JH, Hong SP et al. Feasibility of salvage endoscopic mucosal resection by using a cap for remnant rectal carcinoids after primary EMR. Gastrointest Endosc 2011; 73: 1009-1014

[25] Chen T, Yao LQ, Xu MD et al. Efficacy and Safety of endoscopic submucosal dissection for colorectal carcinoids. Clin Gastroenterol Hepatol 2016; 14: 575-581

[26] Park HW, Byeon JS, Park YS et al. Endoscopic submucosal dissection for treatment of rectal carcinoid tumors. Gastrointest Endosc 2010; 72: $143-149$

[27] Matsushita M, Takakuwa $\mathrm{H}$, Nishio A. Management of rectal carcinoid tumors. Gastrointest Endosc 2003; 58: 641; author reply 641-642

[28] Lee DS, Jeon SW, Park SY et al. The feasibility of endoscopic submucosal dissection for rectal carcinoid tumors: comparison with endoscopic mucosal resection. Endoscopy 2010; 42: 647-651

[29] Fine C, Roquin G, Terrebonne E et al. Endoscopic management of 345 small neuroendocrine tumors: A national study from the French group of endocrine tumors (GTE). United Eur Gastroenterol J 2019; 7: $1102-1112$

[30] Efthymiou M, Taylor AC, Desmond PV et al. Biopsy forceps is inadequate for the resection of diminutive polyps. Endoscopy 2011; 43: 312-316

[31] Anderloni A, Jovani M, Hassan C et al. Advances, problems, and complications of polypectomy. Clin Exp Gastroenterol 2014; 7: 285-296

[32] Zhang Q, Gao P, Han B et al. Polypectomy for complete endoscopic resection of small colorectal polyps. Gastrointest Endosc 2018; 87: $733-740$

[33] Monkemuller KE, Fry LC, Jones BH et al. Histological quality of polyps resected using the cold versus hot biopsy technique. Endoscopy 2004; 36: 432-436

[34] Goldstein NS, Watts JC, Neill JS et al. The effect of electrothermal cautery-assisted resection of diminutive colonic polyps on histopathologic diagnosis. Am J Clin Pathol 2001; 115: 356-361 